\title{
Research on the Wage Gap Between Urban and Rural Labor: Based on CHNS Micro Survey Data
}

\author{
Guangtao Xia ${ }^{1}$, Xinzhen $\mathrm{Xu}^{2}$ \\ ${ }^{1}$ PBC School of Finance, Tsinghua University, Beijing, P. R. China \\ ${ }^{2}$ School of Economics, Shandong University, Jinan, P. R. China
}

Email address:

xiagt@pbcsf.tsinghua.edu.cn (Guangtao Xia),xuxzsdu@163.com (Xinzhen Xu)

\section{To cite this article:}

Guangtao Xia, Xinzhen Xu. Research on the Wage Gap Between Urban and Rural Labor: Based on CHNS Micro Survey Data. International Journal of Economics, Finance and Management Sciences. Vol. 7, No. 6, 2019, pp. 197-202. doi: 10.11648/j.ijefm.20190706.13

Received: October 14, 2019; Accepted: November 16 2019; Published: November 18, 2019

\begin{abstract}
In recent years, there is a substantial debate on the wage differences in China. Yet most empirical studies of wage gap concentrate only on short-run changes due to the lack of high-quality data. In this paper, we study the wage gap between urban and rural labor in China using the Chinese Health and Nutrition Survey (CHNS) data spanning several years. By the methods of OLS regression and Oaxaca decomposition we have two main findings: first, the wage gap resulting from household register discrimination have been gradually decreasing since the Lewis transition, and the growth rate of migrant workers' wages obviously exceeded the accumulation rate of their human capital in 2011; second, the wage disadvantage of the rural labor mainly comes from the weakness of its human capital, compared with that of the urban labor. These findings would remind us of the rising welfare inequality problem in China against the background that the accumulation of human capital on rural labor have slowed down after the Lewis transition. In the end, we come up with several suggestions for policy reform. First of all, the central government should distribute more educational resources into rural areas specifically. In addition, the local government and enterprises should increase specific investment in skills training for migrant workers. Last but not least, the governments ought to gradually abolish the related rules that restrain migrant workers from obtaining urban public services, which will help to equalize the social welfare in China eventually.
\end{abstract}

Keywords: Urban-rural Wage Gap, Lewis Transition, Household Register Discrimination

\section{Introduction}

The household registration system is one of the institutional arrangements with the most Chinese characteristics. Under this kind of system, the rural population is excluded from urban welfare system, and the rural labor force were rejected from non-agricultural jobs [1]. In 1958, the China's household registration segregation system was officially established, which made the situation of "neither blind increase of urban labor force nor blind outflow of rural labor force" last for a long time in Chinese society.

From 1984 to 2019, the Chinese government has issued a series of reform programs on household registration system, aiming to promote population growth in small and medium-sized cities and restrict population growth in big cities. However, many migrant workers still chose to transfer to large cities with the purpose of increasing their income [2]. China achieved rapid development in the three decades from
1978 to 2008 with an annual GDP growth rate of over $9 \%$, relying on the huge cheap rural surplus labor force [3]. However, the long-lasting household registration system leads to the desynchronization between "land urbanization" and "human urbanization" in China. In 2007, China's urbanization rate was $45 \%$, while the proportion of non-agricultural registered population was only $33 \%$ [4]. What's more, China's labor market was divided, which means migrant workers cannot enjoy the preferential wage treatment, employment protection and complete social security that only belongs to urban residents. Obviously, China has the dual economic structure proposed by Lewis. In 2004, the Chinese economy reached the Lewis turning point with the shortage of migrant workers in China's coastal areas spread to other areas quickly. And as a consequence, widespread labor force shortages expanded across the country with the abruptly increases on ordinary workers' wages. In 2010, the growth of working-age population stopped and the demographic dividend 
disappeared, which means the Lewis transition interval ended. Therefore, the Lewis transition interval is usually defined as from the year 2004 to 2010 [5].

Since China's economic system stepped into Lewis turning point, whether the effect of household registration discrimination have been declining on the urban-rural wage gap? What's the main determinants driving the changes on the wage gap? And how to improve the existing system to achieve the income equality? To analyze the above issues, we firstly select four year cross-section data that span the Lewis transition interval. Then we observe the dynamics of the degree of household registration discrimination on the Chinese labor markets before and after the Lewis transition. In addition, the method of Oaxaca decomposition is used to explore the dominant determinants of the urban-rural wage gap. Finally, we propose several policy suggestions based on the main empirical findings.

\section{Literature Review}

Many scholars have studied the wage gap caused by the household registration system between urban and rural labor force. The results of most research show that the proportion of wage gap resulting from household registration discrimination has showed a declining trend, but it still should be not neglected by the authorities. Reference [6] found that discrimination accounted for more than $100 \%$ of the wage gap between urban and rural labor, using the survey data of floating population in Shanghai. According to the survey data collected by the Chinese Academy of Social Sciences, cross-sector wage discrimination in year 2010 was significantly lower than that in 2001 [7].

Recently, in addition to wage discrimination in China's urban labor market, research on occupational discrimination also have been paid much attention by scholars, mainly based on Brown decomposition method [8-11]. Reference [6] analyzed the data of 1995-1996 in Shanghai and claimed that the different payment for equal work was the main determinant of the wage gap between urban and rural workers. Reference [7] observed that the employment segregation still existed in 2010, but the degree of employment segregation and the hourly wage gap caused by household registration discrimination were both greatly reduced, compared with that of 2001. Reference [12] on the contrary, found that the degree of contribution of household registration discrimination to wage gap in year 2013 was greater than that of 2002, using CHIP survey data.

The existing literature explores the wage gap between urban and rural labor force as well as their different career choice, and finds that the household registration discrimination in urban labor market is not conducive to alleviating the labor shortage after Lewis transition, which provides a strong evidence and motive to eliminate household registration discrimination for purpose of promoting fair competition in labor market. However, most of the existing studies mainly focus on short term data, and there are scarce literature exploring the influence of household registration on the urban-rural wage gap with a long period data spanning the whole Lewis' transition process. But two latest papers should not be neglected, one compared the degree of household registration discrimination in 2001 and 2010 [7], while the other used cross-sectional data of 2002 and 2013 to analyze the change of Hukou-based employment discrimination and its influences on the wage gap [12].

\section{Data and Descriptive Statistics}

The data used in this paper are from the Chinese Health and Nutrition Survey (CHNS) conducted by the University of North Carolina in the United States. The data not only contain the health and nutrition status of Chinese residents, but also include the household registration, salary, education, occupation and other individual-level information, which meets the requirements of our research questions. After cleaning up the raw data, our sample size is 1,913 in year 2004, including 499 rural samples and 1,414 urban samples. In 2006, the sample size is 2049 , including 628 rural samples and 1,421 urban samples. In 2009, the sample size is 2342, including 854 rural samples and 1,488 urban samples. In 2011, the sample size is 2301 , including 877 rural samples and 1,424 urban samples.

According to our research questions and appropriate methods, the chosen variables are as follows: hourly wage, household registration, years of education, work experience, gender, position and region. Among them, the hourly wage is calculated through the monthly wage, average number of working days per week and average number of working hours per day. The years of education is defined as the accumulative length of formal schooling, which could be calculated easily from the data set. For example, if the original data shows one's education background is "first grade junior high school", then the years of education would be seven. Jobs are divided into senior, moderate and ordinary positions: the senior position includes advanced technicians, ordinary technicians, regulators, administrators and project managers; the moderate one includes ordinary office staff and skilled workers; the ordinary one including unskilled workers, soldiers, drivers, and other service workers. According to the standard decomposition method, the region is divided into eastern, central and western parts. The eastern part includes Liaoning, Shandong and Jiangsu, the western part includes Guangxi and Guizhou, and the rest belongs to the central part.

Table 1 reflects the change of human capital level and average hourly wage of urban and rural labor force in the chosen four years spanning the Lewis transition. As can be seen from table 1, compared with urban labor force, the human capital level of rural registered labor force is always lower than that of urban labor force, and the gap between them is gradually expanding. Before and after the Lewis transition, the average length of schooling of urban registered labor remained at about 11.5 years, while the average length of schooling of rural registered labor dropped from 9.01 in year 2004 to 8.71 in 2011 , and the gap between them have increased from 2.23 in 2004 to 2.97 in 2011. However, after 
Lewis's transition, the hourly wage gap between urban and rural labor force have been narrowing. In 2004, the hourly wage of urban registered labor force was 1.46 times that of rural registered labor force, and in 2011, it dropped to 1.28 times. From 2004 to 2011, the average annual growth rate of hourly wage of rural registered labor was $14.26 \%$, which was greater than that of urban registered labor $(13.00 \%)$. The excessive growth of migrant workers' wages has significantly negative influences on the accumulation of their human capital, which is malign for the improvement of the average level of migrant workers' human capital.

In terms of work experience, the gap between urban and rural labor force narrowed from 1.1 years in 2004 to 0.08 years in 2009. In 2011, migrant workers had 1.19 years more work experience than urban registered labor force. The working experience of rural registered labor increased from 22.22 years in 2004 to 25.69 years in 2011 .

Table 1. Human Capital Level and Hourly Wage of Urban and Rural Labor force.

\begin{tabular}{|c|c|c|c|c|c|c|}
\hline & \multicolumn{3}{|c|}{ Human Capital Level } & \multicolumn{3}{|c|}{ Average Hourly Wage } \\
\hline & Rural(1) & $\operatorname{Urban}(2)$ & Gap $=(2)-(1)$ & Rural(1) & $\operatorname{Urban}(2)$ & Gap $=(2) /(1)$ \\
\hline & Year 2004 & & & & & \\
\hline Average Years of Education & 9.01 & 11.24 & 2.23 & 4.01 & 5.86 & 1.46 \\
\hline Junior High School or below & $70.94 \%$ & $32.67 \%$ & $-38.27 \%$ & 3.92 & 4.98 & 1.27 \\
\hline High School or above & $29.06 \%$ & $67.33 \%$ & $38.27 \%$ & 4.23 & 6.30 & 1.49 \\
\hline Work Experience & $\begin{array}{l}22.22 \\
\text { Year } 2006\end{array}$ & 23.32 & 1.1 & & & \\
\hline Junior High School or below & $67.99 \%$ & $30.82 \%$ & $-37.17 \%$ & 4.15 & 5.74 & 1.38 \\
\hline High School or above & $32.01 \%$ & $62.18 \%$ & $30.17 \%$ & 5.56 & 8.52 & 1.53 \\
\hline Work Experience & $\begin{array}{l}23.47 \\
\text { Year } 2009\end{array}$ & 24.07 & 0.6 & & & \\
\hline Average Years of Education & 8.81 & 11.59 & 2.78 & 9.31 & 12.24 & 1.31 \\
\hline Junior High School or below & $75.76 \%$ & $32.39 \%$ & $-43.37 \%$ & 8.60 & 9.73 & 1.13 \\
\hline High School or above & $24.24 \%$ & $67.51 \%$ & $43.27 \%$ & 11.51 & 13.44 & 1.17 \\
\hline Average Years of Education & 8.71 & 11.68 & 2.97 & 11.10 & 14.21 & 1.28 \\
\hline Junior High School or below & $74.34 \%$ & $29.85 \%$ & $-44.49 \%$ & 11.18 & 9.78 & 0.87 \\
\hline High School or above & $25.66 \%$ & $70.15 \%$ & $44.49 \%$ & 10.85 & 16.09 & 1.48 \\
\hline Work Experience & 25.69 & 24.50 & -1.19 & & & \\
\hline
\end{tabular}

Source: Authors' calculation based on CHNS database.

\section{The Effect of Household Registration Discrimination on Wage Gap}

The OLS Estimation of Mincer wage equation [13, 14] can directly explore the change of urban-rural wage gap before and after Lewis transition and clarify the impacts of household registration discrimination on the gap. The regression analysis model is specified as follows:

$$
\ln \text { wage }=\beta_{0}+\beta_{1} \text { city }+X \beta+u
$$

The dependent variable, ln wage, represents the natural logarithm of hourly wage of labor force, the independent variable, city, represents urban household registration. And the control variables matrix $\boldsymbol{X}$ include years of education, work experience, square item of work experience, gender (male), type of position (with ordinary position as reference), and region (with western region as reference). The equation examines the impacts of household registration, years of schooling, and work experience on hourly wage. The logarithmic hourly wage of urban registered labor is $\beta_{1}$ more than that of rural registered labor, which reflects the degree of household registration discrimination. The coefficient $\beta_{1}$ is predicted to decrease after Lewis turning point, which means the degree of household registration discrimination will decrease. $u$ stands for disturbance term.

Table 2. OLS Estimation of Mincer Wage Equation on the Whole Sample.

\begin{tabular}{|c|c|c|c|c|}
\hline & 2004 & 2006 & 2009 & 2011 \\
\hline \multirow{2}{*}{ City } & $0.182 * * *$ & $0.155 * * *$ & $0.0763 * *$ & 0.0442 \\
\hline & $(0.0349)$ & $(0.0319)$ & $(0.0326)$ & $(0.0294)$ \\
\hline \multirow{2}{*}{ Years of education } & $0.0576^{* * *}$ & $0.0635 * * *$ & $0.0645^{* * *}$ & $0.0296^{* * *}$ \\
\hline & $(0.00631)$ & $(0.00593)$ & $(0.00637)$ & $(0.00545)$ \\
\hline \multirow{2}{*}{ Work experience } & $0.0225 * * *$ & $0.0228 * * *$ & $0.0191 * * *$ & $0.0161 * * *$ \\
\hline & $(0.00440)$ & $(0.00424)$ & $(0.00419)$ & $(0.00438)$ \\
\hline Square of work experience & $-0.000347 * * *$ & $-0.000407 * * *$ & $-0.000289 * * *$ & $-0.000335 * * *$ \\
\hline \multirow{2}{*}{ Male } & $0.152 * * *$ & $0.230 * * *$ & $0.292 * * *$ & $0.272 * * *$ \\
\hline & $(0.0287)$ & $(0.0275)$ & $(0.0286)$ & $(0.0259)$ \\
\hline Senior post & $0.252 * * *$ & $0.308 * * *$ & $0.321 * * *$ & $0.414 * * *$ \\
\hline
\end{tabular}




\begin{tabular}{lllll}
\hline & $\mathbf{2 0 0 4}$ & $\mathbf{2 0 0 6}$ & $\mathbf{2 0 0 9}$ & $\mathbf{2 0 1 1}$ \\
\hline & $(0.0378)$ & $(0.0372)$ & $(0.0394)$ & $(0.0366)$ \\
Medium post & $0.132^{* * *}$ & $0.136^{* * *}$ & $0.131^{* * *}$ & $0.193^{* * *}$ \\
& $(0.0364)$ & $(0.0339)$ & $(0.0349)$ & $(0.0315)$ \\
Eastern region & $0.0775^{* *}$ & $0.0786^{* *}$ & $0.0903^{* *}$ & $0.180^{* * *}$ \\
& $(0.0383)$ & $(0.0370)$ & $(0.0376)$ & $(0.0332)$ \\
Central region & 0.00131 & $0.0851^{* *}$ & $0.150^{* * *}$ & $0.103^{* * *}$ \\
& $(0.0392)$ & $(0.0378)$ & $(0.0386)$ & $(0.0363)$ \\
Constant & $0.162^{*}$ & $0.224^{* * *}$ & $0.645^{* * *}$ & $1.358^{* * *}$ \\
Observations & $(0.0887)$ & $(0.0859)$ & $(0.0907)$ & $(0.0812)$ \\
Adj R-squared & 1,913 & 2,049 & 2,342 & 2,301 \\
\hline
\end{tabular}

Note: $* * * \mathrm{p}<0.01, * * \mathrm{p}<0.05, * \mathrm{p}<0.1$

Table 2 shows the regression results of the mincer equation from 2004 to 2011. From 2004 to 2009, the coefficient of the variable "urban household registration" ( $\left.\beta_{1}\right)$ have decreased from 0.182 to 0.0763 . In 2011, this coefficient $\beta_{1}$ was no longer significant, indicating that the wage gap caused by the household registration decreases after the Lewis transition under the condition of identical individual endowments and positions. The rate of return on education increased from 0.0576 in year 2004 to 0.0645 in 2009 . The salary income of men was always significantly higher than that of women. The coefficient of senior positions increased from 0.252 to 0.414 . Reference [12] also found that the proportion of the wage gap between urban and rural labor force resulting from household registration discrimination dropped from $16.98 \%$ in year 2002 to $-40.05 \%$ in 2013 , and the wage gap between migrant workers and urban workers in year 2013 mainly came from the difference in human capital level between the two groups. Based on the change of the coefficient of "urban household registration" $\left(\beta_{1}\right)$ in mincer's equation, this paper draw the similar conclusion that the contribution of household registration discrimination to wage gap decreases after Lewis' transition.

\section{The Determinants of Urban-rural Wage Gap: Based on Oaxaca Decomposition}

Taking into account the heterogeneous impacts of other variables on wage gap, we decomposes the determinants of wage gap between urban and rural labor force through Oaxaca decomposition method $[15,16]$, and defines the wage equation of urban registered labor force as the non-discriminatory benchmark. The decomposition equation is as follows:

$$
\ln \overline{W_{C}}-\ln \overline{W_{R}}=\left(\overline{X_{C}}-\overline{X_{R}}\right) \widehat{\beta_{C}}+\overline{X_{R}}\left(\widehat{\beta_{C}}-\widehat{\beta_{R}}\right)
$$

Subscript $C$ represents urban household registration, $\mathrm{R}$ represents rural household registration, and the control variables matrix $\boldsymbol{X}$ is identical to that of formula (1). The first component on the right of equation (2) represents the wage gap caused by individual characteristic difference between urban and rural labor, and the second component represents the wage gap resulting from household registration discrimination.

The decomposition results are shown in Table 3. Obviously, the overall proportion of the characteristic difference have increased from $59.09 \%$ in year 2004 to $111.15 \%$ in 2011 , and the overall coefficient difference between 2009 and 2011 was no longer significant, indicating that the urban-rural wage difference could be completely explained by individual characteristic difference. It illustrates that the wage discrimination caused by household registration system have decreased after the Lewis turning point, and furthermore, the discrimination even disappeared in year 2009, which means the China's labor market became more competitive.

However, from the perspective of human capital, the average length of education of the rural labor force was always lower than that of the urban, and the gap between them exhibited a widening trend. As a consequence, the wage gap caused by the difference in years of education has been rising from year 2004 to 2009 .

Based on the total change of coefficient difference, the declining trend indicates that the mode of wage determination for urban and rural labor has been converging, while the degree of wage discrimination has been shrinking. In year 2009 and 2011, the coefficient difference is no longer significant. However, from the perspective of various influencing factors, there are still some problems that need to be paid more attention. From 2004 to 2009, the difference in education returns was narrowing, which indicates that the role of human capital in wage discrimination was getting closer between the two groups. However, the coefficient difference expanded again to about $77 \%$ in year 2011 , which was mainly caused by the large human capital gap between urban and rural areas. In the same year, $74.34 \%$ of the rural registered labor received education less than junior high school, while $70.15 \%$ of the urban ones received education more than senior high school. In addition, this difference $(0.534)$ is offset by spontaneous wage growth (-0.699), reflecting thatthe wage growth rate of migrant workers exceeds the growth rate of their human capital after Lewis transition. 
Table 3. The Oaxaca Decomposition of the Urban-rural Wage Gap.

\begin{tabular}{|c|c|c|c|c|c|}
\hline \multirow{2}{*}{ Year 2004} & \multirow{2}{*}{$\begin{array}{l}\text { Total gap } \\
\text { (In) }\end{array}$} & \multicolumn{2}{|l|}{ Characteristic difference } & \multicolumn{2}{|l|}{ Coefficient difference } \\
\hline & & Gap(ln) & Percentage (\%) & Gap (In) & Percentage (\%) \\
\hline Years of education & 0.422 & $0.149 * * *$ & 35.31 & $0.273 * *$ & 64.69 \\
\hline Work experience & 0.0404 & $0.0184 * * *$ & 45.54 & 0.022 & 54.46 \\
\hline Male & -0.02131 & $-0.00881 * *$ & 41.34 & -0.0125 & 58.66 \\
\hline Type of post & 0.06787 & $0.0747 * * *$ & 110.06 & -0.00683 & -10.06 \\
\hline Region & 0.00098 & 0.000665 & 67.86 & 0.000315 & 32.14 \\
\hline Constant & -0.113 & & & -0.113 & 100.00 \\
\hline Total & 0.396 & $0.234 * * *$ & 59.09 & $0.162 * * *$ & 40.91 \\
\hline \multirow{2}{*}{ Year 2006} & Total gap & \multicolumn{2}{|c|}{ Characteristic difference } & \multicolumn{2}{|l|}{ Coefficient difference } \\
\hline & $(\ln )$ & $\operatorname{Gap}(\ln )$ & Percentage (\%) & Gap $(\ln )$ & Percentage (\%) \\
\hline Years of education & 0.525 & $0.189 * * *$ & 36.00 & $0.336 * * *$ & 64.00 \\
\hline Work experience & 0.2339 & $0.0199 * * *$ & 8.51 & $0.214 * *$ & 91.49 \\
\hline Male & -0.0647 & $-0.0137 * *$ & 21.17 & -0.051 & 78.83 \\
\hline Type of post & 0.0257 & $0.0958 * * *$ & 372.76 & $-0.0701 * * *$ & -272.76 \\
\hline Region & 0.00211 & 0.00435 & 206.16 & -0.00224 & -106.16 \\
\hline Constant & -0.312 & & & $-0.312 *$ & 100.00 \\
\hline Total & 0.409 & $0.295 * * *$ & 72.13 & $0.114 * * *$ & 27.87 \\
\hline \multirow{2}{*}{ Year 2009} & Total gap & \multicolumn{2}{|c|}{ Characteristic difference } & \multicolumn{2}{|l|}{ Coefficient difference } \\
\hline & $(\ln )$ & Gap $(\ln )$ & Percentage (\%) & Gap $(\ln )$ & Percentage (\%) \\
\hline Years of education & 0.536 & $0.210 * * *$ & 39.18 & $0.326 * * *$ & 60.82 \\
\hline Work experience & 0.04371 & $0.00721 *$ & 16.50 & 0.0365 & 83.50 \\
\hline Male & -0.0886 & $-0.0143^{* *}$ & 16.14 & $-0.0734 *$ & 82.84 \\
\hline Type of post & -0.021 & $0.123 * * *$ & -585.71 & $-0.144 * * *$ & 685.71 \\
\hline Region & 0.00073 & $0.00965 * *$ & 1321.92 & -0.00892 & -1221.92 \\
\hline Constant & -0.126 & & & -0.126 & 100.00 \\
\hline Total & 0.34541 & $0.336 * * *$ & 97.39 & 0.00941 & 2.73 \\
\hline \multirow{2}{*}{ Year 2011} & Total gap & \multicolumn{2}{|c|}{ Characteristic difference } & \multicolumn{2}{|l|}{ Coefficient difference } \\
\hline & $(\ln )$ & Gap $(\ln )$ & Percentage $(\%)$ & Gap $(\ln )$ & Percentage $(\%)$ \\
\hline Years of education & 0.694 & $0.160 * * *$ & 23.05 & $0.534 * * *$ & 76.95 \\
\hline Work experience & 0.35538 & 0.00338 & 0.95 & $0.352 * * *$ & 99.05 \\
\hline Male & -0.11565 & -0.00165 & 1.43 & $-0.114 * * *$ & -98.57 \\
\hline Type of post & 0.013 & $0.117 * * *$ & 900.00 & $-0.104 * * *$ & -800.00 \\
\hline Region & 0.014162 & $0.0144 * *$ & 101.68 & -0.000238 & -1.68 \\
\hline Constant & -0.699 & & & $-0.699 * * *$ & 100.00 \\
\hline Total & 0.2636 & $0.293 * * *$ & 111.15 & -0.0294 & -11.15 \\
\hline
\end{tabular}

Note: $* * * \mathrm{p}<0.01, * * \mathrm{p}<0.05, * \mathrm{p}<0.1$

\section{Conclusion}

Through the study of the urban-rural wage gap before and after Lewis transition, we have several important findings. Firstly, the effect of household registration discrimination on wage gap have gradually narrowed after Lewis's transition, and the growth rate of migrant workers' wages exceeded the improving speed of their human capital level due to the existence of compensatory wages. In 2004, the urban-rural wage gap caused by household registration discrimination accounted for $40.91 \%$, which decreased to $27.87 \%$ in 2006 . After 2009, the effect of discrimination was no longer significant on wage differences, indicating that the efficiency of Chinese labor market and the situation of rural labor were improving. In 2011, the proportion of wage gap resulting from discrimination accounted for $-11.15 \%$, which means the household registration system began to narrow the wage gap between urban and rural labor force.

Secondly, the accumulation speed of human capital of rural labor have been slowing down since Lewis transition. The low wage level of rural labor mainly came from the disadvantage of their human capital accumulation. The part of wage gap resulting from the characteristic difference between urban and rural labor have increased from $59.09 \%$ in 2004 to $111.15 \%$ in 2011.

According to the above empirical analysis, we also put forward the following policy suggestions on how to alleviate the scarcity of ordinary labor force and improve the welfare level of migrant workers sustainably.

First and foremost, we should improve the education level of migrant workers and their children: one the one hand, the central government should distribute more educational resources into rural areas specifically for the purpose of closing the quality gap between urban and rural education; on the other hand, enterprises should strengthen on-the-job training for migrant workers in order to improve their labor skill to meet the needs of industrial structure upgrading.

In addition, the existing barriers to enjoy urban education resources for migrant workers should be removed as soon as possible. Through the reform of the household registration system, migrant workers and their children can obtain fair education resources, so that migrant workers can form stable expectations of their future income and actively attend more skills trainings. Local governments and enterprises should increase specific investment in skills training for migrant workers, so as to improve their human capital level and 
promote local economic development for the long run [17].

Last but not least, the government ought to abolish the related rules that restrain migrant workers from obtaining urban public services, and also strive to increase the effective coverage of public services for migrant workers in urban areas, which will help to ensure the long-term free flow of labor resources, improve migrant workers' sense of achievement and happiness, and eventually narrow the gap between urban and rural welfare as well.

\section{References}

[1] Fang Cai, Meiyan Wang. Why Hasn't Labor Mobility Narrowed the Rural-urban Income Gap? Economic Perspectives, 2009 (08): 4-10.

[2] Jiangli Zhu, Zilian Li. Hukou System Reform, Individuals Flows and Regional Disparities: Based on the Intertemporal Model of Heterogeneous Individuals Flows. China Economic Quarterly, 2016, 15 (02): 797-816.

[3] John Knight, Quheng Deng and Shi Li. The Shortage of China's Peasant-workers, and the Surplus of the Rural Labor Force in China. Management World, 2011 (11): 12-27+187.

[4] Fang Cai. Demographic Transition, Demographic Dividend, and Lewis Turning Point in China. Economic Research Journal, 2010 .

[5] Fang Cai. Understanding the Past, Present, and Future of China's Economic Development: Based on A Unified Framework of Growth Theories. Economic Research Journal, 2013, 48 (11): 4-16+55.

[6] Xin Meng, Junsen Zhang. The Two-Tier Labor Market in Urban China: Occupational Segregation and Wage Differentials between Urban Residents and Rural Migrants in Shanghai. Journal of Comparative Economics, 2001, 29 (3): $0-504$.
[7] Jingfang Sun. Changes to Hukou Discrimination in China's Labor Market: Employment and Wages of Rural Migrant Workers. Economic Research Journal, 2017, 52 (08): 171-186.

[8] Randall S. Brown, Marilyn Moon, and Barbara S. Zoloth. Incorporating Occupational Attainment in Studies of Male-Female Earnings Differentials. Journal of Human Resources, 1980, 15 (1): 3-28.

[9] Pak-Wai Liu, Xin Meng, and Junsen Zhang. Sectoral Gender Wage Differentials and Discrimination in the Transitional Chinese Economy. Journal of Population Economics, 2000, 13 (2): 331-352.

[10] Xin Meng. Male-female Wage Determination and Gender Wage Discrimination in China's Rural Industrial Sector. Labour Economics, 1998, 5 (1): 67-89.

[11] Doris Weichselbaumer, Rudolf Winter - Ebmer. A Meta-Analysis of the International Gender Wage Gap. Journal of Economic Surveys, 2005, 19 (3): 479-511.

[12] Li Zhang and Binbin Wu. Hukou-based Employment Discrimination and Its Effect on Earnings Differentials: 2002 --2013. Studies in Labor Economics, 2019, 7 (03): 84-99.

[13] Jacob Mincer. The Distribution of Labor Incomes: A Survey with Special Reference to the Human Capital Approach. Journal of Economic Literature, 1970, 8 (1): 1-26.

[14] Jacob Mincer. Schooling, Experience, and Earnings. Human Behavior \& Social Institutions No. 2. 1974.

[15] Alan S. Blinder. Wage Discrimination: Reduced Form and Structural Estimates. The Journal of Human Resources, 1973, 8 (4): $436-455$

[16] Ronald Oaxaca. Male-Female Wage Differentials in Urban Labor Markets. International Economic Review, 1973, 14 (3): 693.

[17] Ming Lu. Great State Needs Bigger City: The Unity, Development and Balance of Contemporary China, Shanghai: Shanghai people's Publishing House, 2016. 